\title{
Organizational Culture and HR Practices Impact on Firm Performance
}

\author{
Mannava Sumaja $^{{ }^{* 1}}$, Dr. Y Chitra Rekha ${ }^{2}$, Dr. Kolachina Srinivas ${ }^{3}$ \\ ${ }^{1}$ Research Scholar, KL University, Guntur, AP, India \\ ${ }^{2}$ Associate Professor, Department of MBA, Audisankara College of Engineering and Technology (Autonomous), Gudur, AP, India. \\ ${ }^{3}$ Associate Professor, K L University, Guntur, AP, India
}

\begin{abstract}
The managing human resource is a typical task. The multicultural employee attitude managing with merge of organizational culture, which influence HR practices. The functions of organization impact its culture of host and home nation. Culture will impact employee attitude, which reflect on work style. The information collected from various research studies and survey for primary data source from three different IT companies
\end{abstract}

Keywords - HR Practices; Organizational Culture; Effectiveness; Employee Attitude

\section{Introduction}

Today's competitive environment are continuously espoused to be an organization's culture and its HR practices, both of which influence the behavior of organizational members, the deliberate selection of candidates who share the desired values which reinforce the organization's cultural norms[1]. Recruitment and selection within a global context is a complex issue and HR managers need to be careful in carrying out recruitment activities in different cultural contexts. National culture could also be a crucial moderator of relationships between recruitment activities and outcomes across all phases of the recruitment process. By taking different cultural values into consideration, firms may be able to have an advantage over competitors when building up the most important resources of organizations, their people such as recruitment and selection explore the cultural values influence the effectiveness of recruitment practices in different cultural contexts [2].

In a world where organizations continually have to reinvent themselves in the face of constant change it is important that they recognize that their employees are the ultimate source of value. So the onus is on HR to ensure that in fulfilling their functions of recruiting, selecting, training, rewarding, motivating and appraising they are sensitive to the immense changes occurring in both the internal and external environments. HR policies and practices need to reflect changing demographics, social trends, economic conditions, technology, legislation and culture. These include ensuring that the planning process recognizes the value of its people from the start; seeing that top level decision makers recognize the HR implications of their proposals; designing and managing the culture, climate and organizational processes of the business to ensure that everyone does their job better and that highcaliber people are found and retained; reviewing the levels of commitment throughout the organization and making improvements where necessary; and assessing the performance requirements needed to achieve the business objectives [3]. Through alternative ways like changing organizational culture where employees are encouraged to freely discuss and exchange ideas. Therefore, if managers are trained to use the transformational leadership behaviors discussed during this study, they'll help subordinates become more intrinsically motivated to place extra efforts into trying out new and artistic approaches to their problems [4]. It's suggested that a developmental culture is that the ape-man in-between HR system and innovation outcomes. An HR system which emphasizes extensive training, performance-based reward, and team development is important to make an organizational culture that's conducive to product innovation. The organizational culture acted as a mediator between a firm's HR system and product innovation [5]. Then creation of knowledge assets or the performance of knowledge transfer. Therefore, it is necessary for organizations to consider some of the elements that show are the relationship between organizational elements and the performance of knowledge transfer. Five main independent variables were identified organizational culture, organizational structure, technology, people/human resources and political directives and these were tested against creation of knowledge assets and knowledge transfer performance [6]. Human resource management (HRM) decisions are likely to have an important and unique influence on organizational performance [7]. Human resources that predict the direct and interact with effect of HR practices and organizational culture on firm performance. It goes beyond and static equilibrium mindset by identifying the dynamic and co-specialized resources needed proactively to anticipate and respond to environmental changes. It is a comprehensive study that has effectively integrated industrial economics and organizational theories [8].

An increasing number of studies indicate that HR systems don't lead on to performance. Instead, researchers propose to think about the intermediate linkages between 
HR systems and performance (Katou and Budhwar 2006). Most of the prior studies found that employee attitudes (satisfaction and commitment) and climate (shared perception of HR) were the key mediating factors. Boselie, Paauwe and Jansen (2001) found that employee satisfaction, motivation, retention, social climate and involvement mediate the relationship between HR practices and firm performance [9]. The purpose of this study is to understand how firms sustain a competitive advantage through the effective management of people [10]. The organizational culture is categorized by behavioral norms [10] Organizational culture and HR practices are the significant and positive correlations with organizational performance [11].

Dyer and Reeves (1995) The relationship between HR practices and performance and proposed that measures of performance into four categories. First, employee outcomes affect the results of the practices on employees like their attitudes and behavior, particularly behavior like absenteeism and turnover. Organizational outcomes specialise in more operational measures of performance like productivity, quality and shrinkage, many or all of which might be precursors to profitability. Financial / accounting outcomes ask the particular financial performance measures and include expenses, revenues and profitability. Finally, marketbased outcomes reflect how the financial markets value a firm, particularly stock price or variations of it [12].

The significant impact of $\mathrm{HR}$ practices and organizational commitment on the operating performance and profitability of business units, the role of transaction costs in examining HR utsourcing [13]. In Multinational companies surveyed in practical manner, expatriate managers, and culturally diverse workforces. Globalization requires the successful management of diversity. Multinational companies with worldwide subsidiaries need to recognize and appreciate the impact of culture on organizational values and practices to be able to successfully transfer management know-how to various local units [14]. The frame work of the relationship between HR practices on organizational performance by specifying the influence the internal social structure of the organizations [15]. In this study provides evidence for the hypothesis that human resource practices influence organizational climate which in turn influences customer satisfaction indices. The current study provides some understanding of the manner in which human resource practices influence organizational outcomes [16].

\section{Analysis}

To determine the effectiveness of organizational culture and HR practices on employee productivity.

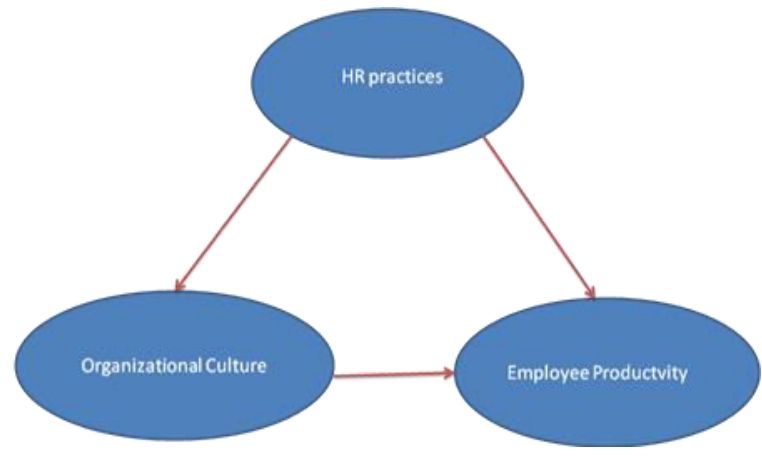

Fig.1: Difference between organizational culture and HR practices

There is a significant difference between organizational culture and HR practices on employee productivity.

Here,

$\mathrm{X}=$ Organizational culture,

$\mathrm{M}=$ HR practices,

Y1= Employee productivity.

\subsection{Model 1}

Run MATRIX procedure:

*********** PROCESS Procedure for SPSS Version $3.3 * * * * * *$

Written by Andrew F. Hayes, Ph.D. www.afhayes.com Documentation available in Hayes (2018). www.guilford.com/p/hayes3

$$
\begin{gathered}
\text { Model : } 4 \\
\mathrm{Y}: \mathrm{Y} 1 \\
\mathrm{X}: \mathrm{x} \\
\mathrm{M}: \mathrm{M}
\end{gathered}
$$

Sample

Size: 108

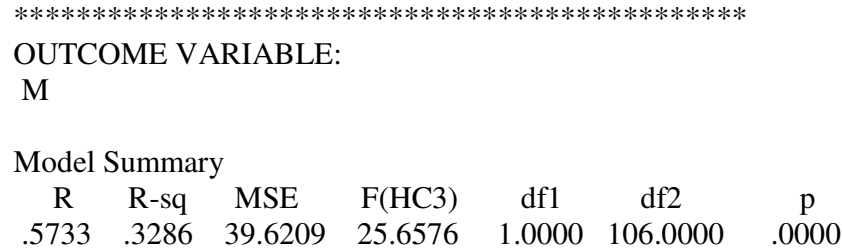

Model

$\begin{array}{ccccccr} & \text { coeff } & \text { se }(\text { HC3 }) & \mathrm{t} & \mathrm{p} & \text { LLCI } & \text { ULCI } \\ \text { constant } & 8.7270 & 7.1415 & 1.2220 & .2244 & -5.4316 & 22.8857 \\ \mathrm{x} & .3549 & .0701 & 5.0653 & .0000 & .2160 & .4937\end{array}$

Standardized coefficients coeff

x $\quad .5733$ 
Form the above table, it is evident from the case 2, that the mediating variable plays a vital role. To examine the impact of organizational culture and HR practices on firm performance.

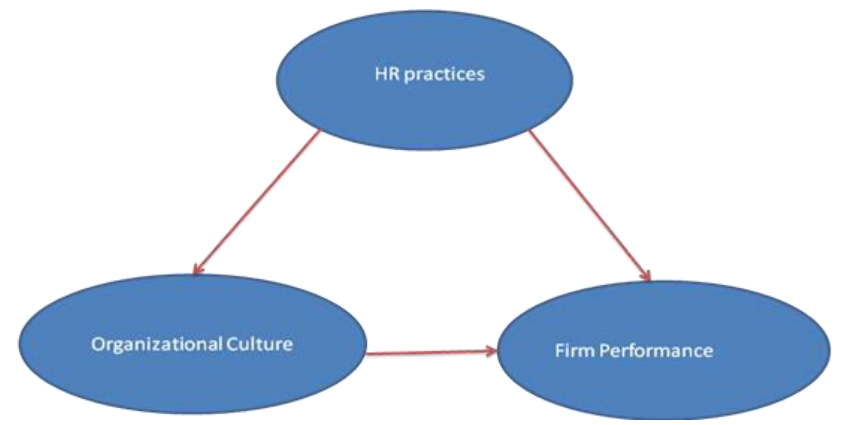

Fig.2: relation between Organizational culture and HR practices

There is a significant relation between Organizational culture and HR practices on firm performance.

Here,

$\mathrm{X}=$ Organizational culture,

$\mathrm{M}=\mathrm{HR}$ practices,

Y2= Firm Performance.

\subsection{Model 2}

Run MATRIX procedure:

********* PROCESS Procedure for SPSS Version $3.3 * * * * * * * *$

Written by Andrew F. Hayes, Ph.D. www.afhayes.com Documentation available in Hayes (2018). www.guilford.com/p/hayes3

$* * * * * * * * * * * * * * * * * * * * * * * * * * * * * * * * * * * * * * * * * * * * * * * * *$
Model $: 4$
$\mathrm{Y}: \mathrm{Y} 2$
$\mathrm{X}: \mathrm{x}$
$\mathrm{M}: \mathrm{M}$

Sample

Size: 108

$* * * * * * * * * * * * * * * * * * * * * * * * * * * * * * * * * * * * * * * * * * * * * * * * * * * *$

OUTCOME VARIABLE:

$\mathrm{M}$

Model Summary

$\begin{array}{ccccccc}\mathrm{R} & \mathrm{R}-\mathrm{sq} & \mathrm{MSE} & \mathrm{F}(\mathrm{HC} 3) & \mathrm{df1} & \mathrm{df} 2 & \mathrm{p} \\ .5733 & .3286 & 39.6209 & 25.6576 & 1.0000 & 106.0000 & .0000\end{array}$

Model

$\begin{array}{llllll}\text { coeff } & \mathrm{se}(\mathrm{HC} 3) & \mathrm{t} & \mathrm{p} & \text { LLCI } & \text { ULCI }\end{array}$

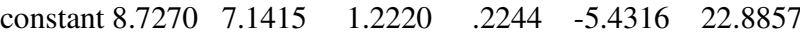

$\begin{array}{lllllll}\mathrm{x} & .3549 & .0701 & 5.0653 & .0000 & .2160 & .4937\end{array}$
Standardized coefficients

coeff

X $\quad .5733$

Covariance matrix of regression parameter estimates:

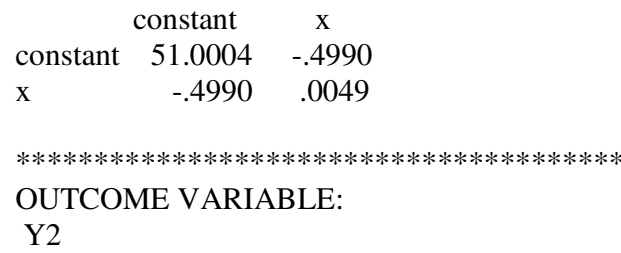

Model

$\begin{array}{lcccccc} & \text { coeff } & \mathrm{se}(\mathrm{HC} 3) & \mathrm{t} & \mathrm{p} & \text { LLCI } & \text { ULCI } \\ \text { constant } & 5.3782 & 3.6096 & 1.4900 & .1392 & -1.7790 & 12.5354 \\ \mathrm{x} & -.0325 & .0328 & -.9906 & .3242 & -.0976 & .0326 \\ \mathrm{M} & .7501 & .0520 & 14.4174 & .0000 & .6469 & .8532\end{array}$

Standardized coefficients coeff

x $\quad-.0645$

M .9206

Covariance matrix of regression parameter estimates: constant $\mathrm{x} \quad \mathrm{M}$

$\begin{array}{llll}\text { constant } & 13.0292 & -.0913 & -.0882\end{array}$

$\begin{array}{llll}\mathrm{X} & -.0913 & .0011 & -.0003\end{array}$

$\begin{array}{llll}\mathrm{M} & -.0882 & -.0003 & .0027\end{array}$

************ TOTAL EFFECT MODEL $* * * * * * * * * * * * * *$ OUTCOME VARIABLE:

$\mathrm{Y} 2$

Model Summary

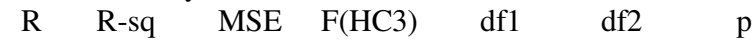
$\begin{array}{lllllll}.4633 & .2146 & 30.7697 & 26.8429 & 1.0000 & 106.0000 & .0000\end{array}$

Model

coeff se(HC3) t $\quad p \quad$ LLCI ULCI

$\begin{array}{llllll}\text { constant } 11.9241 & 4.5961 & 2.5944 & 0108 & 2.8119 & 21.0363\end{array}$

$\begin{array}{lllllll}\mathrm{x} & .2337 & .0451 & 5.1810 & .0000 & .1442 & .3231\end{array}$

Standardized coefficients coeff

x $\quad .4633$

Covariance matrix of regression parameter estimates: constant $\mathrm{x}$

constant $21.1241-.2061$

$\begin{array}{lll}\mathrm{x} & -.2061 \quad .0020\end{array}$

* TOTAL, DIRECT, AND INDIRECT EFFECTS OF X ON Y *

Total effect of $\mathrm{X}$ on $\mathrm{Y}$

Effect se(HC3) t p LLCI ULCI c_ps c_cs

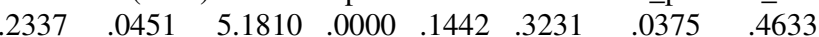


Direct effect of $\mathrm{X}$ on $\mathrm{Y}$

Effect se(HC3) t p LLCI ULCI c'_ps c'_cs

$\begin{array}{lllllll}-.0325 & .0328 & -.9906 .3242 & -.0976 & .0326 & -.0052 & -.0645\end{array}$

Indirect effect(s) of $\mathrm{X}$ on $\mathrm{Y}$ :

Effect BootSE BootLLCI BootULCI

$\begin{array}{lllll}\text { M } & .2662 & .0488 & .1669 & .3591\end{array}$

Partially standardized indirect effect(s) of X on Y:

Effect BootSE BootLLCI BootULCI

$\begin{array}{lllll}\text { M } & .0427 & .0072 & .0280 & .0566\end{array}$

Completely standardized indirect effect(s) of X on Y:

Effect BootSE BootLLCI BootULCI

$\begin{array}{lllll}\text { M } & .5277 & .0980 & .3288 & .7105\end{array}$

***** ANALYSIS NOTES AND ERRORS *****

Level of confidence for all confidence intervals in output: 95.0000

Number of bootstrap samples for percentile bootstrap confidence intervals: 5000

NOTE: A heteroscedasticity consistent standard error and covariance matrix estimator was used.

\section{END MATRIX ----}

Result - The above results indicate that the mediation variable (M) is highly influential than the direct variable $X$ on Y1, Models with mediation and without mediation are all significant. The model with mediation is highly significant than the model without mediation variable as $\mathrm{p}$ values are less than 0.05 .

Table 2: Interpretation of Model 2

\begin{tabular}{|c|c|c|c|c|c|}
\hline Cases & $\begin{array}{c}\text { Regression } \\
\text { Equation }\end{array}$ & $\mathbf{R}$ & $\mathbf{R}^{2}$ & $\begin{array}{c}\mathbf{p}- \\
\text { value }\end{array}$ & $\begin{array}{c}\text { Interpretation } \\
1\end{array}$ \\
\hline $\begin{array}{c}\text { Case } \\
\text { X on M }\end{array}$ & 0.5733 & 0.3286 & 0.001 & $\begin{array}{c}\text { There is a } \\
\text { moderate } \\
\text { correlation and } \\
\text { model explains } \\
32.86 \text { variance } \\
\text { in DV }\end{array}$ \\
\hline $\begin{array}{c}\text { Case } \\
2\end{array}$ & $\begin{array}{c}\mathrm{X} \text { and M } \\
\text { on Y2 }\end{array}$ & 0.8852 & 0.7836 & 0.001 & $\begin{array}{c}\text { There is a very } \\
\text { strong } \\
\text { correlation and } \\
\text { model explains } \\
\text { 78.36\% } \\
\text { variance in } \\
\text { DV }\end{array}$ \\
\hline Case & $\mathrm{X}$ on Y2 & 0.4633 & 0.2146 & 0.001 & $\begin{array}{c}\text { There is a } \\
\text { moderate } \\
\text { correlation and } \\
\text { model explains } \\
\text { 21.46\% } \\
\text { variance in } \\
\text { DV }\end{array}$ \\
\hline
\end{tabular}

Form the above table, it is evident from the case 2, that the mediating variable plays a major role.

\section{Conclusion}

The organizational culture linking with recruitment and selection, planning, organizing, motivating, staffing, directing, controlling and rewarding of managed employee attitude. Organizational culture is also impact on socioeconomic conditions of internal and external environment. HR policies and practices got to reflect changing demographics, social trends, economic conditions, technology, legislation and culture. The mediating role of implementation and organizational culture in the employee attitude and firm performance linked. Moderating the business objectives as per current scenario for satisfy employee and stake holders. These processes by which a performance of work system affects firm performance. The statistically proven the internal and external environment are connected with organizational culture and HR practices. On firm performance and employee productivity are impacted by organizational culture and HR practices. The organizational culture dilute with framing and implementation of HR practices. Father research scope is detailed HR practices impacts.

\section{Reference}

[1] An Expert HR System for Aligning Organizational Culture and Strategy, Elizabeth F. Cabrera Jaime Bonache Published 1999 in Human Resource Planning Vol. 22, no. 1, 51-60

[2] Recruiting across cultures: A value-based model of recruitment, Authors: Rong Ma, David G Allen, Human Resource Management Review, Volume 19, Issue 4, December 2009, Pages 334-346, https://doi.org/10.1016/j.hrmr.2009.03.001

[3] Managing Human Resources, $4^{\text {th }}$ edition, By Raymond J. Stone, prepared by Andrew Zur, University of Melbourne, Wiley, John Wiley \& Sons Australia, Ltd.

[4] Transformational and Transactional Leadership and Their Effects on Creativity in Groups Dong I. Jung Published online: 08 Jun 2010, Creativity Research Journal Publication details, including instructions for authors and subscription information: http://www.tandfonline.com/loi/hcrj20

5] The HR system, organizational culture, and product innovation, Authors: Chung Ming Lau, Hang-Yue Ngo, International Business Review 13 (2004) 685-703, Received 5 February 2004; received in revised form 6 July 2004; accepted 20 August 2004

[6] Knowledge management in a public organization: A study on the relationship between organizational elements and the performance of knowledge transfer, Journal of Knowledge management, volume 8, issue 2, Authors: Syed Omar Sharifuddin Syed-Ikhsan, Fytton Rowland.

[7] The Impact of Human Resource Management on Organizational Performance: Progress and Prospects, Authors: Brian Becker and Barry Gerhart, Academy of Management Journal Vol. 39, No. 4, Published Online:30 Nov 2017, https:// doi.org/ $10.5465 / 256712$

[8] In search of sustained competitive advantage: the impact of organizational culture, competitive strategy and human resource management practices on firm performance, Author: Lismen L.M. Chan , Margaret A. Shaffer \& Ed Snape (2004), The International

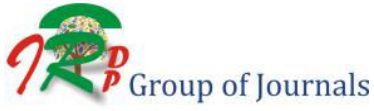


Journal of Human Resource Management, 15:1, 17-35, DOI: $10.1080 / 0958519032000157320$.

[9] The roles of implementation and organizational culture in the HRperformance link, Authors: Irene Hau-Siu Chow (2012) , The International Journal of Human Resource Management, 23:15, 3114 3132, DOI: 10.1080/09585192.2011.639553.

[10] Behavioral Norms and Expectations: A Quantitative Approach To the Assessment of Organizational Culture, Robert A. Cooke and Denise M. Rousseau, Group \& Organization Management 1988 13: 245, DOI: $10.1177 / 105960118801300302$

[11] In search of sustained competitive advantage: the impact of organizational culture, competitive strategy and human resource management practices on firm performance, Lismen L.M. Chan , Margaret A. Shaffer \& Ed Snape (2004), The International Journal of Human Resource Management, 15:1, 17-35, DOI: $10.1080 / 0958519032000157320$.

[12] The impact of HR practices on the performance of business units, Patrick M. Wright, Cornell University, Timothy M. Gardner, Brigham Young University, Lisa M. Moynihan, London Business School, Human Resource Management Journal, Vol 13 No 3, 2003, pages 21-36.

[13] HR Outsourcing and its impact the role transaction costs, BRIAN S. KLAAS, The Darla Moore School of Business Administration
University of South Carolina, JOHN MC CLENDON, School of Business and Management, Rmple University.

[14] Thomas W. Gainey, the Darla Moore School of Business Administration, University of South Carolina.

[15] Organizational Culture and Human resource management practices, The Model of Culture Fit, Zeynep Aycan, Koç University, Turkey, Rabindra N. Kanungo, McGill University, Montreal, Canada, JAI B.

P. SINHA, ASSERT Institute of Management Studies, India, Downloaded from jcc.sagepub.com at UNIV OF NEW HAMPSHIRE on March 5, 2015.

[16] High-Performance Work Systems and Organizational Performance: The Mediating Role of Internal Social structure, W. Randy Evans and Walter D. Davis, Journal of Management 2005 31: 758, http://jom.sagepub.com/content/31/5/758, The online version of this article can be found at: DOI: 10.1177/0149206305279370.

[17] Human resource practices, organizational climate, and customer satisfaction, Kirk L. Rogga, David B. Schmidta, Carla Shulla, Neal Schmittb, * aAon Consulting, 63 Kercheval, Grosse Pointe Farms, MI 48236, USA, Journal of Management 27 (2001) 431-449, bDepartment of Psychology, Michigan State University, 135 Snyder Hall, East Lansing, MI 48824-1117, USA, Received 13 March 2000; received in revised form 28 August 2000; accepted 18 October 2000. 